\title{
Arranjos domésticos e estrutura urbana na Região Metropolitana de São Paulo (2010)
}

\author{
Household arrangements and urban structure \\ in the Metropolitan Region of São Paulo (2010)
}

Pier Francesco De Maria [I] Luiz Antonio Chaves de Farias [II]

\begin{abstract}
Resumo
Os anos 1960 e 1970 trouxeram mudanças nas estruturas espacial urbana e familiar, principalmente nos países desenvolvidos, com alterações nas macroestruturas de trabalho e residência e com o surgimento de novos arranjos domiciliares. Relacionar a família e a (re)estruturação do espaço urbano, em vista da reprodução material dos indivíduos que a compõem, é o objetivo deste trabalho. Analisamos a Região Metropolitana de São Paulo (RMSP), onde os arranjos urbanos e domiciliares são mais complexos e diversificados. Construímos uma tipologia que traduziu a estrutura do espaço urbano em função do mercado de trabalho e das áreas residenciais. Posteriormente, sobrepusemos a distribuição dos arranjos domiciliares e da vulnerabilidade social. Utilizando o Censo de 2010, analisamos as relações das diferentes variáveis para as áreas de ponderação.
\end{abstract}

Palavras-chave: Região Metropolitana de São Paulo; estrutura urbana; arranjo doméstico.

\begin{abstract}
The 1960s and 1970s brought changes to urban and family spatial structures, especially in developed countries, with transformations in work and residence macrostructures and emergence of new household arrangements. This paper aims to relate families to the (re) structuring of the urban space, considering the material reproduction of its individuals. We analyze the Metropolitan Region of São Paulo, where the urban and household arrangements are more complex and diversified. We constructed a typology that translated the structure of the urban space according to the labor market and residential areas. Then, we superimposed on it the distribution of household arrangements and social vulnerability. Using the 2010 Census, we analyzed the relationships of different variables for the weighting areas.
\end{abstract}

Keywords: Metropolitan Region of São Paulo; urban structure; household arrangement. 


\section{Introdução}

As décadas de 1960 e 1970 marcaram o início de sensíveis mudanças nos arranjos urbanos e familiares. Se assistimos, para os primeiros, a alterações em suas macroestruturas de trabalho e residência, para os segundos, tornou-se também evidente 0 crescimento, em termos de representatividade, de outros arranjos para além do nuclear burguês. Dadas as mudanças nas relações sociais de produção nas cidades, configuram-se novas divisões econômicas e sociais do espaço, mediadas pelos mercados de trabalho e imobiliário. No entanto, a reestruturação urbana não se restringe às mudanças na indústria. As alterações nas formas e funções dos diferentes segmentos do espaço urbano, a ela vinculadas, também possuem componentes que repousam na escala dos indivíduos e da família.

Nesse sentido, a família exerce um importante papel no conjunto de mudanças descritas acima, já que, de acordo com Bilac (1995), pode ser apropriada como a instituição mediadora entre indivíduo (escala micro) e sociedade (escala macro). Conhecer as relações da família com outras dimensões da vida social, em especial sua localização no espaço urbano em vista da reprodução social dos indivíduos que a compõem (acesso a instituições sociais, como trabalho, escola, sistema de saúde, etc.), pode elucidar as mudanças em curso no espaço urbano. Buzar, Ogden e Hall (2005) chegam a evocar as unidades domésticas ${ }^{1}$ como agentes modeladores do ambiente urbano, imbricados nas conexões com as mudanças socioeconômicas em questão, ocasionadas, de um lado, pela soma das transformações dos arranjos familiares, e, de outro, pelas grandes mudanças no meio urbano.
A Região Metropolitana de São Paulo (RMSP), região privilegiada neste artigo, aparece como um excelente laboratório para a proposta aqui sugerida, por concentrar cerca de $10 \%$ da população brasileira $(19,7$ milhões de pessoas), em 2010, e ter uma mancha urbana contínua de mais de 2 mil km². Além disso, apresenta-se como uma das áreas em estágio mais avançado da transição demográfica no Brasil, tendo níveis de fecundidade significativamente abaixo da taxa de reposição (valor definido em 2,1 filhos por mulher).

Do ponto de vista de sua estrutura urbano-produtiva, igualmente se coloca como uma das áreas urbanas brasileiras mais avançadas no processo de reestruturação, tendo em vista que, de acordo com Cunha (1994), já nos anos 1980, via-se uma ruptura parcial dos padrões vigentes até então, que seguiam o modelo núcleo-periferia. Isso porque se observou o deslocamento de um amplo contingente populacional para municípios periféricos em vista dos mercados de trabalho que se abriam nessas áreas, destacando-se a alta seletividade por arranjos familiares desses fluxos migratórios. Recentemente, Nakano (2015) chamou a atenção para os novos padrões de ocupação populacional do núcleo metropolitano, salientando o expressivo aumento da participação de arranjos domésticos relacionados à baixa densidade de ocupação, como aqueles unipessoais.

Diante desse contexto, o objetivo do presente trabalho é conhecer as relações da família com outras dimensões da vida social, em especial a apropriação do espaço urbano em vista da reprodução social dos indivíduos na RMSP. Partimos da hipótese de que os efeitos sociais das transformações vividas pela família nos últimos anos se estendem para muito 
além do domínio convencional das tendências meramente demográficas. A complexificação das estruturas familiares pode ser conectada a uma gama muito maior de processos sociais, incluindo o surgimento de novas redes de parentesco e amizade, bem como mudanças nos significados das vidas cotidiana e doméstica (Buzar, Ogden e Hall, 2005). Isso ocorre porque as cidades moldam e, simultaneamente, são moldadas por práticas de consumo e padrões de mobilidade de suas famílias constituintes.

Considerando esses elementos, na segunda seção, apresenta-se uma breve visão do processo de heterogeneização dos arranjos familiares, assim como da discussão na qual se encontra envolvida (tese da Segunda Transição Demográfica). Em seguida, delineia-se o que se entende, neste trabalho, por reestruturação urbana. Na terceira seção, apresentam-se as possíveis imbricações existentes entre os dois processos em questão para, em seguida, propor um aporte metodológico que permita apreender empiricamente as referidas relações. Antes de tecer as considerações finais deste trabalho, são apresentados os resultados a respeito do método proposto para o estudo das interações entre os arranjos familiares e a estrutura urbana.

\section{Elementos teóricos}

\section{A heterogeneização dos arranjos familiares}

Os anos 1960 e 1970 marcaram transformações expressivas na vida privada da população, especialmente nos países europeus e norte-americanos. Novas oportunidades ampliaram as alternativas de escolha para homens e mulheres, com repercussões notórias sobre 0 regime sociodemográfico que se seguiu a partir de então. Champion (2001) corrobora essa visão, afirmando que, embora superficialmente pareça uma continuação da experiência de transição demográfica original (associada mais fortemente com a queda da mortalidade e da fecundidade), o regime emergente difere em vários aspectos. Mais notavelmente, este se relaciona com os novos padrões de nupcialidade, incluindo (mas não se limitando a): 0 aumento da coabitação antes do casamento; o aumento da idade média da fecundidade; e os níveis mais elevados de dissolução das uniões. Todos esses elementos, aparentemente, são impulsionados pelo crescimento de novos valores e práticas sociais ligadas ao individualismo e à emancipação feminina.

Se o último fator é relativamente aceito pela literatura enquanto componente do processo em questão, a tese do individualismo, vinculada ao conceito de pós-materialismo, merece ser vista com mais critério, tendo em vista a sua não operacionalidade efetiva. Além disso, a não universalidade das mudanças sociodemográficas consideradas requer igualmente olhá-las com certas restrições. De fato, conformariam um movimento mais geral de mudança na sociedade, que poderia ser denominado efetivamente com uma Segunda Transição Demográfica. ${ }^{2}$ Recorrentemente, os autores apresentados ao longo deste trabalho não tiveram esse cuidado em suas análises, o que os levou a cometer certas imprecisões analíticas, sem, no entanto, comprometer os fios condutores de suas discussões.

Polêmicas conceituais à parte, segundo Oliveira, Marcondes e Vieira (2015), foram os 
fatores de natureza estrutural - material e cultural - que compuseram o cenário de mudança, o qual empurrou as novas gerações em direção à modernidade, sendo dois deles com particular importância: a escolarização e o trabalho feminino no mercado. No que toca ao âmbito específico das famílias e da vida privada:

[...] as mudanças pouco a pouco introduzidas nas relações de gênero constituíram o principal eixo de transformações. As gerações do pós-guerra ecoaram bandeiras do feminismo europeu e norte-americano, embaladas na onda libertária que arrebatou contingentes jovens em praticamente todo o Ocidente. Novos valores e práticas seguem afrontando conceitos e criando oportunidades para a experimentação social à medida que avançamos no século XXI. (Ibid., p. 5)

As autoras seguem em suas elucubrações, afirmando que tais mudanças são igualmente decorrentes de alterações profundas no regime demográfico, consolidado especialmente a partir da década de 1960. Tal período é marcado por um intenso declínio da fecundidade, consequência das mudanças de caráter estrutural e, ao mesmo tempo, condicionante de outras transformações na vida privada que se seguiram.

Vinculado a esse processo se dá o enveIhecimento populacional, fruto da redução de tamanho das coortes mais jovens, e o prolongamento da vida; esses fatores abriram caminho para a redefinição das transições geracionais e suas inter-relações. Essas transformações, de caráter estrutural, ainda estão adidas à ampliação da disponibilidade de meios eficazes de controle dos nascimentos, assim como à generalização da demanda por seu uso. Isto expressa a incorporação da ideia de ter filhos como uma escolha e não um destino (particularmente feminino), envolvendo cada vez mais segmentos sociais diversos.

Em termos empíricos, Clark e Whiters (2007) ressaltam os efeitos das mudanças descritas nos parágrafos anteriores sobre as estruturas familiares dos Estados Unidos, contexto espacial de formulação das ideias dos principais autores aqui considerados. Segundo os autores, em 1970, apenas $6 \%$ das pessoas entre 30 e 34 anos não eram casadas, mas, em 2002, esse número subiu para 34\%. Em geral, os americanos tornaram-se menos propensos a se casar: o número de casamentos de mulheres de 15 anos ou mais caiu de mais de 75 para 40 por mil nos últimos 34 anos. Casais com filhos menores de 18 anos diminuíram de cerca de $90 \%$ para cerca de $70 \%$ nas últimas três décadas.

Como efeito de tal arcabouço de mudanças para fins de nossa análise, Clark (1987) destaca que uma das questões fundamentais na compreensão da reestruturação urbana diz respeito a quais os impactos da diminuição do tamanho dos arranjos domiciliares, do aumento das famílias chefiadas por mulheres e dos arranjos domésticos unipessoais sobre a estrutura da cidade, especialmente em uma era de diminuição do poder de compra dos domicílios. Certamente, isto impactará sobre a maneira como as famílias selecionarão e utilizarão os recursos urbanos. 
Reestruturação urbana e novos padrões de mobilidade

Antes de definir o que se entende por reestruturação urbana e o que ela representa para o processo de urbanização e para a mobilidade das famílias na metrópole, é importante definir o que é estrutura urbana. Sposito (2004, p. 311) apresenta esse conceito como a "forma como se encontram dispostos e se articulam os usos do solo, num dado momento do contínuo processo de estruturação dos espaços da cidade", pautados pelas divisões social e técnica do trabalho. Com base nessa definição, a autora justifica e defende o uso do sufixo "(aç)ão" ao se fazer referência à estrutura urbana, uma vez que o processo é contínuo e dinâmico. Nesse sentido, estruturação, desestruturação e reestruturação urbana seriam faces de um mesmo processo (Farias, 2013).

Embora essa definição dê conta do que é estrutura urbana, faz-se necessário cotejá-la com a diferenciação, pontuada por Santos (2008), entre estruturação urbana e estruturação da cidade. Isto seria importante, segundo Farias (2013), uma vez que a urbanização é um processo, enquanto a cidade é sua concretização:

Nesse sentido, é interessante articular a proposta de Sposito (2004) à de Santos (1996) utilizando a expressão estruturação urbana para identificar o conteúdo e as contradições, continuidades e descontinuidades, ações e reações associadas ao processo de urbanização. Essa estruturação urbana, entendida a partir do sistema de ações que garante a reprodução do espaço urbano, ao mesmo tempo que por esse passa a ser determinada. E a expressão estruturação das cidades para identificar a materialização de tais processos, continuidades e continuidades territoriais, ações e reações, no nível intra-urbano, pensando no sistema de objetos. (Santos, 2008, s/p)

Corroborando com o mesmo raciocínio, Villaça nos alerta para o uso equivocado do conceito de "estrutura urbana" como sinônimo de "espaço urbano". Para ele:

Estrutura, quando se refere a espaço urbano, diz respeito à localização relativa dos elementos espaciais e suas relações, ou seja, dos centros de negócios (não só o principal, mas também os demais) das áreas residenciais segregadas e, finalmente, das áreas industriais. (Villaça, 1999, p. 33)

Nesse sentido, para Villaça (ibid.), a renovação do espaço urbano não é garantia de reestruturação do espaço (Farias, 2013). De acordo com Sposito (2004), para que ocorra a reestruturação urbana, é preciso que se materializem mudanças expressivas na posição, na natureza e na localização das áreas residenciais e industriais e de negócios, "determinando alterações nos padrões espaciais dos fluxos e das relações de hierarquia, concorrência, co-operação e complementaridade, estabelecidos entre eles" (Farias, 2013, p. 6). Portanto, a reestruturação urbana envolve:

[...] ações e [...] sujeitos que redefinem a forma como os solos urbanos passam a ser utilizados, visando atender a uma nova lógica. Todavia, tais mudanças são tão profundas que implicam uma redefinição, também, do modo como estava organizada a estrutura urbana. (Santos, 2008, s/p) 
Isto nos mostra que o processo de reestruturação, embora possa parecer a mera "substituição de uma estrutura velha por outra completamente nova" (Farias, 2013, p. 3), contrasta com uma dinâmica rígida e fixa. 0 motivo disso, na visão de Soja (1993), seria o conjunto necessário de fluxos, transições e transações, com permanências e continuidades que dão ao processo um caráter essencialmente dinâmico. Em outros termos, Gomes (2011) pontua que a reestruturação só poderá se concretizar à medida que "as estruturas socioespaciais necessárias à acumulação se tornam gargalos para alavancar o crescimento e, consequentemente, a produção e a reprodução do capital" (ibid., p. 55).

Em síntese, a partir do momento em que as estruturas existentes não mais satisfazem as necessidades do capital e os "remendos adaptativos já não se mostram mais suficientes" (ibid.), urge a realização de uma mudança estrutural no meio urbano, à qual se dá o nome de reestruturação (Soja, 1993). Nesse sentido, a reestruturação estaria "entre a reforma parcial e a transformação revolucionária, entre a situação de perfeita normalidade e algo completamente diferente" (ibid., p. 194).

0 processo de reestruturação produtiva, atrelado à reestruturação urbana, seria "resultado e condicionante da emergência de uma nova fase no desenvolvimento do modo de produção capitalista, em escala global, analisada por Harvey (1993) e por Benko (1996), como regime de acumulação flexível, e por Soja (1993), como especialização flexível" (Santos, 2008, s/p). Tal reestruturação se sustenta em três pilares básicos, a saber: "[...] as mudanças nas relações de produção e trabalho (reestruturação produtiva); a ampliação e diversificação dos sistemas de modalidade de bens, serviços e pessoas; e as mudanças de padrões de consumo com ampliação e densificação dos mercados" (Ribeiro, 2009, p. 126). Observa-se, assim, que a reestruturação produtiva:

[...] provocou modificações no processo de urbanização, acarretando alterações nos papéis que as cidades desempenham na rede urbana, reestruturando a própria rede urbana, assim como no processo de estruturação urbana, já que as cidades assumiram uma nova lógica como produto e determinante do regime de acumulação flexível. (Santos, 2008, s/p)

Nesse sentido, os territórios moldam-se a partir de meios que assegurem celeridade à reprodução ampliada do capital e às diferentes estratégias do capitalismo (Farias, 2013), e essa dinâmica se transforma e é transformada pelo "território das cidades" (Ribeiro, 2009). Nessa direção, as cidades ganham novos contornos, tais como:

[...] incremento e adensamento de elementos, como o automóvel e os meios de comunicação e informação; novas tecnologias de comunicação e transporte; novos embates políticos e econômicos entre os diferentes agentes produtores do espaço urbano; novas estratégias de incorporações urbanas; e maior complexidade da divisão social e territorial do trabalho, produzem modificam as localizações das atividades produtivas, redefinem a estruturação das redes urbanas; novas dinâmicas e práticas de consumo; necessidades de fluxos, com direções, sentidos e intensidade modificados, alterando a circulação nas cidades e entre as cidades. (Ibid., pp. 131-132) 
Observa-se que "os padrões clássicos de segregação residencial, especialmente aqueles advindos da Escola de Chicago, não dão mais conta de explicar totalmente a disposição das classes sociais no espaço intraurbano" (Farias, 2013, p. 8). Isso se daria, segundo Sposito (2004), pela complexificação da estrutura urbana, na qual passam a coexistir "periferias" no centro e "centralidades" na periferia. Novas centralidades têm surgido nas periferias urbanas, "destronando o centro tradicional de sua posição até então quase que absoluta sobre determinados aspectos e funções" (Farias, 2013, p. 9): a esse fenômeno tem se chamado de polinucleação urbana (Davanzo et al., 2011). Para Champion (2001), que se dedicou a estudar a dimensão populacional desse processo, isto sugere a multiplicidade de pontos nos quais serviços e empregos podem ser acessados pelos residentes.

Segundo o Champion (ibid., p. 666; tradução livre), "tal transformação, de uma região urbana de centro único para outra de centros múltiplos, é acompanhada por alterações na geografia dos preços do solo e, consequentemente, das áreas residenciais". Deve-se salientar, todavia, que, embora muitos países desenvolvidos tenham passado por um intenso processo de contraurbanização e desconcentração populacional durante os anos 1960 e 1970, essa onda foi recentemente seguida (ou, em alguns casos, acompanhada) por uma reversão, com a reocupação das áreas centrais das aglomerações urbano-metropolitanas por meio da revitalização e da renovação urbana (Soja, 1993).

\section{Possíveis interações?}

Conforme pôde se observar, o emparelhamento (temporal e espacial) dos fenômenos apreciados nos tópicos anteriores, tendo em vista ocorrerem predominantemente no meio urbano, suscitam hipóteses que resguardem possíveis imbricações entre eles. Se o processo de urbanização já foi recorrentemente visto como correlato ao fenômeno da transição demográfica, possuindo muitas interações com ela, guardadas algumas exceções (Therborn, 2006), por que, mais recentemente, em uma nova fase dos processos de urbanização e de transformações das famílias (seja esta uma Segunda Transição Demográfica ou não), essas interações também não seguiram novas relações, próprias das novas complexidades assumidas por eles?

Apesar da incipiente literatura que tentou responder à questão acima, percebe-se que tal relacionamento é considerado de maneira relativamente rudimentar, por parte dos estudiosos especializados nas transformações da família, assim como também daqueles originários dos estudos urbanos. Os primeiros tendem a se apropriar do grau de urbanização para correlacionar as mudanças em curso na sociedade. Entende-se que esse indicador não mais descreve as complexidades em curso na sociedade considerada, tanto no meio urbano quanto no meio rural, cujo pressuposto de dicotomia existente já se encontra relativamente superado.

Pelo lado dos estudos urbanos, a visão das transformações demográficas é resguardada de certas imprecisões que, em determinados momentos, podem conduzir a algumas 
conclusões falaciosas. Conceitos como o de Segunda Transição Demográfica e de cursos de vida individual (e ciclo de vida familiar) são utilizados acrítica ou indistintamente, o que confunde o leitor em certas ocasiões. No entanto, deve-se ressaltar a importância das contribuições de Clark (1987) e Champion (2001) para o debate em pauta, ilustrado pelo esquema da Figura 1.

Para Champion (2001), as novas tendências demográficas (e as consequentes mudanças na composição populacional) ajudaram a promover novas formas de assentamento, em conjunto com os efeitos da reestruturação econômica e as mudanças tecnológicas. Alternativamente, as mudanças nos padrões de assentamentos produzidos por estes últimos fatores são causadoras ou, pelo menos, condicionantes das alterações no perfil e na composição da população. No âmbito específico da mobilidade residencial, essas relações podem ser verificadas, uma vez que o controle da fecundidade e a instabilidade das famílias se encontram associados às mudanças no padrão geral de preferências residenciais da população como um todo.

A esse respeito, a literatura sobre migração está repleta de evidências da crescente

Figura 1 - Evolução das mudanças no regime demográfico e na estrutura urbana (1950-2025)

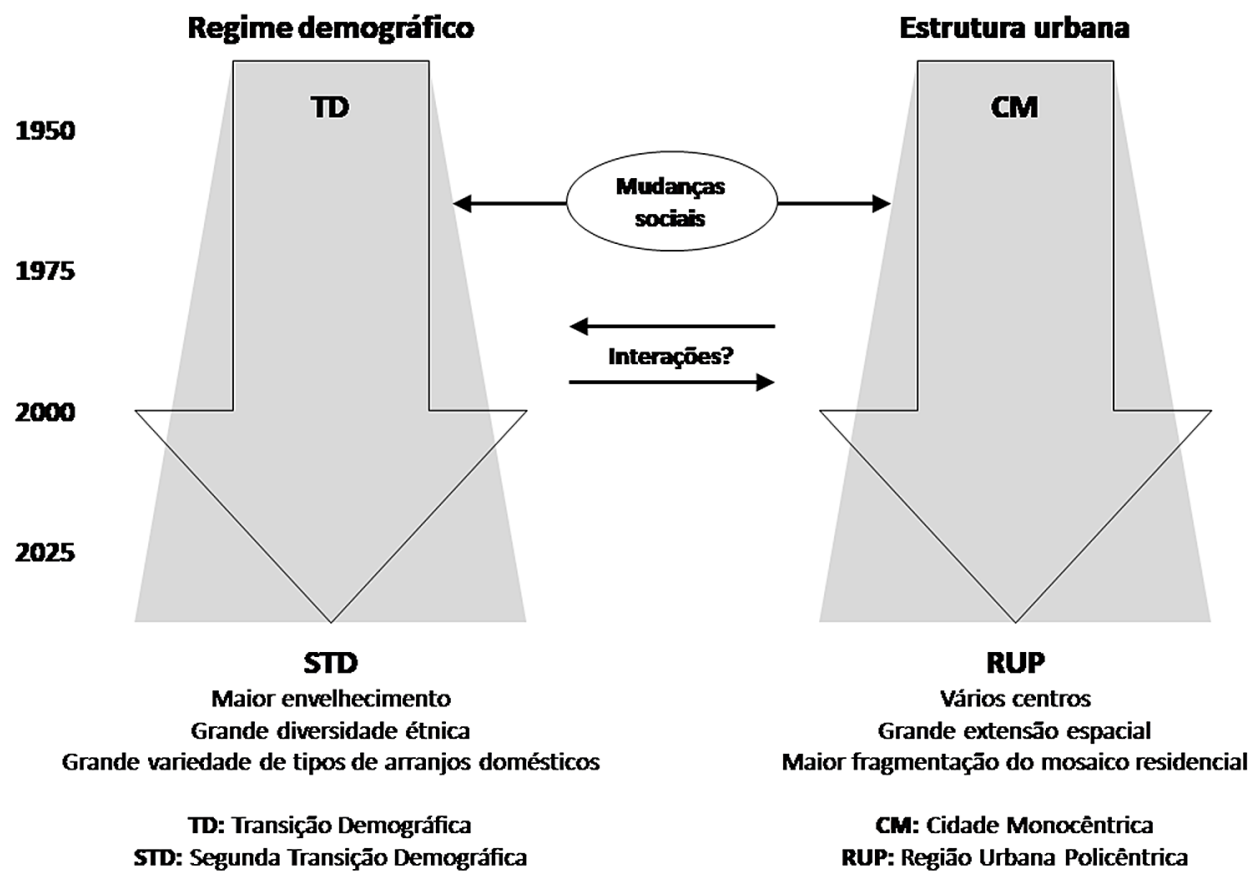

Fonte: Champion (2001, p. 658; tradução dos autores). 
importância do estilo de vida e da qualidade de vida enquanto fatores para estimular as mudanças de residência e a escolha do destino (Findlay e Rogerson, 1993). Em particular, para o processo de reestruturação urbano-metropolitana, esse tema se liga fortemente às correntes de contraurbanização (movimentos populacionais para o espaço periurbano), por um lado; e, com a mesma clareza, por outro lado, a processos de gentrificação e reocupação dos espaços, até então degradados, dos centros das cidades (Champion, 2001).

A perspectiva de análise das possíveis interações dos processos de transformação do espaço urbano e dos arranjos familiares é ainda corroborada por Buzar, Ogden e Hall (2005), que defendem o caráter de agência urbana ou agente modelador do espaço urbano, por parte dos agregados domésticos. Para os autores, muitas das teorizações acerca da vida social intrafamiliar baseiam-se na crença mais ampla de que a vida cotidiana tanto surge da produção social do espaço, quanto a ela está implicada.

Conhecida, de modo geral, a natureza das relações entre as mudanças dos regimes demográficos e das estruturas urbanas, apresenta-se, a seguir, uma visão detalhada de alguns arranjos domiciliares e da estrutura urbano-metropolitana com a qual se vinculam na produção social do espaço.

\section{Arranjos promotores de dispersão}

\section{Arranjos com idosos}

0 envelhecimento populacional tende a tornar mais comuns os arranjos domiciliares com e de idosos, ${ }^{3}$ colocando-os como importantes agentes modeladores do espaço urbano. Nesse sentido, segundo Champion (2001), nas principais regiões metropolitanas americanas, os aposentados tendem a procurar regiões com invernos mais quentes, paisagens com mais amenidades naturais, bons serviços e um ritmo mais lento de vida. A metrópole monocêntrica, que impõe uma mobilidade cotidiana maior por parte de seus habitantes, no sentido de prover suas necessidades de reprodução social, mostra-se menos afeita a tais demandas do que as policêntricas, onde a probabilidade de esses requisitos serem satisfeitos é maior.

Deve-se considerar, como salientam Bennett e Dixon (2006), que se, de fato, essa é uma realidade dos idosos funcionais que possuem uma rede de apoio intradomiciliar, há, também, uma tendência evidente de aumento dos domicílios unipessoais composto por idosos. Estes, nas aglomerações urbanas com estrutura monocêntrica, tendem a se concentrar nas áreas centrais ou nos setores de alto status socioeconômico contíguos a eles, onde podem suprir suas necessidades de acesso a serviços para a reprodução social, sem a necessidade de grandes deslocamentos urbanos. Esse último contexto encontra paralelos nas metrópoles brasileiras, que veem seus centros cada vez mais envelhecidos nos últimos anos.

\section{Arranjos domésticos da família nuclear burguesa}

A estrutura urbana mononuclear, desde o surgimento dos primeiros subúrbios americanos, encontra-se concatenada à consolidação da família nuclear burguesa enquanto "modelo ideal de família" (Champion, 2001). 0 planejamento urbano, especialmente por meio das leis de zoneamento urbano, parece influenciado 
pelas necessidades desse arranjo. De fato, as áreas externas à cidade verticalizada (tradicionais subúrbios americanos) têm sido historicamente vistas como os lugares ideais para as mães cuidarem de seus filhos e para todo o processo de reprodução social, longe do congestionamento e das pressões do núcleo central para o qual o único provedor masculino da família precisa realizar deslocamentos diários (Knox, 1994).

Todavia, conforme aponta Champion (2001), a tendência de reconfiguração de papéis nessa família tende a mudar as demandas de produção social do espaço metropolitano previstas até as décadas de 1970 e 1980. A entrada das mulheres dessas famílias no mercado de trabalho implica contradições resultantes das desigualdades de gênero historicamente construídas na sociedade, as quais ultrapassam a estrutura familiar, tornando-se igualmente evidentes na forma como elas consomem o espaço urbano-metropolitano.

Conciliar o trabalho com as funções domésticas leva a uma restrição dos espaços de vida $^{4}$ das mulheres nas metrópoles. No caso das aglomerações urbanas monocêntricas, isto se torna uma dificuldade, já que a dissociação entre os espaços de trabalho e residência é maior. Segundo Champion (ibid.), isso significa um "cabo de guerra" entre as mães, em suas casas suburbanas, e os empregadores, localizados no núcleo da cidade. Essa "guerra" tem sido amplamente ganha pelas mães que trabaIham, levando a uma enorme descentralização do trabalho.

Além disso, mas tão eloquente quanto, mostra-se o aumento na proporção de mulheres que não têm intenção de se tornarem mães. Isto significa, além da perda de importância do modelo familiar nuclear, uma redução no número de famílias que procuram ambientes suburbanos, contendo casas com jardins, boas escolas públicas e outros serviços comunitários, conforme poderá ser visto nos próximos dois subitens.

\section{Arranjos domiciliares promotores da innercity}

\section{Casais DINC (Double Income No Children)}

Segundo Alves, Cavenaghi e Barros (2010, p. 15), a família DINC tem se consolidado enquanto arranjo domiciliar "em um contexto de generalização da regulação da fecundidade, da entrada da mulher no mercado de trabalho e de uma legislação civil mais igualitária em termos de padrões matrimoniais". Ainda segundo os autores, embora casais com dupla renda que não querem ter filhos seja uma tendência bastante atual, esse tipo de arranjo familiar mais parece um "fenômeno que vem ganhando destaque e que não parece ser uma moda passageira" (ibid.), especialmente nas grandes cidades, onde as condições sociodemográficas descritas acima são mais proeminentes.

Desse modo, de acordo com Champion (2001), em vista de suas demandas por emprego e lazer, os casais DINC são atraídos a residirem nos grandes centros urbanos (innercity) ${ }^{5}$ das metrópoles monocêntricas, nos quais encontram maior acessibilidade a tais atrativos. Dada tal perspectiva de consumo do espaço urbano, o referido autor chega a questionar o papel dos casais DINC como agentes modeladores do espaço que contribuíram efetivamente para o processo de polinucleação vivenciado por algumas aglomerações urbano-metropolitanas. Para o autor, é provável que eles não tenham 
constituído um agente ativo nessa tendência. Uma vez que o desenvolvimento de múltiplas centralidades urbanas é dependente de uma melhora substancial na mobilidade intraurbana, esse grupo pode sentir que a residência próxima aos locais de emprego já não seja tão essencial, vindo a ocupar áreas que não sejam necessariamente a innercity.

\section{Domicílios unipessoais}

As tendências apontadas para o modelo anterior são mais pronunciadas no caso dos arranjos unipessoais, especialmente aqueles constituídos por jovens. As redes sociais desses domicílios, destituídas dos horizontes impostos pela família nuclear burguesa, têm redefinido suas concepções de amizade, família e compromisso; isto levou à criação de novas paisagens sociais, econômicas e culturais urbanas (Watters, 2003). Ademais, partes da estrutura urbano-metropolitana serão mais aproveitadas por esses arranjos em sua reprodução social. Dado o intenso processo, ressaltado por Clark (1987) e Oliveira Marcondes e Vieira (2015), entre outros autores nacionais e internacionais que se dedicaram ao tema, de diminuição do tamanho dos arranjos domiciliares, o tipo aqui considerado pode estar produzindo uma ampla mudança na estrutura das grandes metrópoles do mundo desenvolvido.

Hall e Ogden (2003) salientam que o processo em questão se coloca em curso a partir da década de 1990, com o povoamento das áreas centrais de algumas metrópoles. Tal tendência foi acompanhada de um significativo processo de gentrificação, antes do qual se havia vivenciado um esvaziamento econômico e populacional. A investigação dos autores sobre a natureza dos domicílios do centro da cidade revelou que, de fato, eles são dominados por arranjos domésticos unipessoais. Estes incluem dois grandes grupos: um dos jovens com compromisso de curto prazo para a residência no centro da cidade; e outro, mais heterogêneo, de moradores que se comprometem a viver nesse espaço por um longo período.

Para Champion (2001), no entanto, a despeito de essa realidade, como ocorrido com os casais DINC, ser afeita a uma estrutura metropolitana monocêntrica, pode-se especular que, numa metrópole polinucleada, a tendência em questão seria menos propícia. Isso porque, com faculdades e empregos distribuídos de maneira mais uniforme em toda a região urbana, haveria menos necessidade de residir perto dos centros. De fato, o movimento de heterogeneização sociodemográfica, como apontado por Cunha (2011), das periferias das grandes metrópoles brasileiras, depõe a favor dessa hipótese.

\section{Aproximações metodológicas}

Tendo em mente as possíveis interações entre família e estruturação do espaço urbano acima desenvolvidas, cabem duas perguntas. Como utilizar os dados brasileiros para fazer uma aproximação da temática, considerando as limitações inerentes às fontes de dados quantitativas? Ademais, quais variáveis e métodos podem ser utilizados, de maneira efetiva, para obter resultados preliminares que permitam desenhar interações e relações entre espaço urbano e família (com especial enfoque na dimensão do trabalho), dos componentes da última no primeiro? 
Para realizar essa aproximação, optou-se por utilizar os dados do Censo Demográfico de 2010, que permite analisar dimensões que podem servir de proxy para cada um dos temas acima discutidos. Além disso, a unidade espacial de análise da amostra do Censo é a área de ponderação, que favorece a discussão das relações espaciais intramunicipais e permite captar concentrações de tipos específicos em certas áreas de um município ou de uma região metropolitana. Ainda que o Censo Demográfico seja decenal, uma análise como a proposta neste estudo precisa de uma discussão a respeito da dinâmica intraurbana que pesquisas por amostra, como a Pnad, não comportam.

Para essa análise exploratória, escoIheu-se a Região Metropolitana de São Paulo (RMSP), que pode ser usada como representação mais bem-acabada, no território nacional, da complexidade que uma metrópole pode assumir, na qual a Primeira Transição Demográfica já se esgotou e há elementos mais visíveis da Segunda Transição. Ademais, a escolha da RMSP justifica-se pelo considerável volume populacional, pelos intensos fluxos pendulares e pela existência de atividades diversificadas por todo o seu território - incluindo, dentre outros, os setores de serviços, financeiro, administrativo e industrial. Por fim, sob a ótica urbana, a RMSP é a de maior área metropolitana do Brasil, além de ter a maior área conurbada.

A escolha de se usar apenas o Censo de 2010 justifica-se por dois motivos principais. Primeiramente, pela possibilidade (inexistente no Censo de 2000) de analisar a pendularidade dos trabalhadores na RMSP, segundo outras dimensões, para além da simples localização das áreas de residência e trabalho, o que facilita a análise nos diferenciais desses fluxos por atividade. Em segundo lugar, por ser um momento no qual os níveis de fecundidade já atingiram patamares abaixo do nível de reposição $(2,1$ fiIhos por mulher), o que também guarda relação com a mudança na participação de diversos arranjos familiares no total de famílias (além de maior peso de arranjos não familiares, como os domicílios unipessoais).

Após justificar a escolha da unidade de análise e do período, apresentam-se o método e as variáveis empregadas. Cabe ressaltar que as variáveis escolhidas são aproximações para as dimensões apresentadas anteriormente (que também consideram as limitações de uma pesquisa quantitativa). Propõe-se uma regionalização construída a partir das variáveis selecionadas, que representam as três dimensões abordadas neste texto: (1) a diversificação dos arranjos domiciliares; (2) as imbricações entre pendularidade e atividades; e (3) o padrão espacial da vulnerabilidade social. Tal regionalização é feita a partir de uma análise de agrupamentos, de modo a verificar o padrão espacial existente entre arranjos familiares, distribuição espacial da vulnerabilidade social e estrutura urbana.

Para aproximar as dimensões analisadas neste trabalho, serão utilizadas as seguintes variáveis, disponíveis nos microdados da amostra do Censo Demográfico de 2010. As primeiras duas servem para analisar a estrutura urbana, enquanto as outras servem para delinear a composição dos arranjos familiares e seus rendimentos:

- V0662 - Tempo habitual de deslocamento para o trabalho;

- V6472 - Código da atividade (segundo a CNAE); 
- V5020 - Número da família (única ou convivente);

- V5080 - Rendimento familiar per capita em salários mínimos;

- V5030 - Tipo de unidade doméstica;

- V5090 e V5100 - Tipo de composição familiar.

Adicionalmente às variáveis, para aproximar a estrutura urbana e a composição familiar, é utilizado - para analisar a vulnerabilidade e a estratificação social - o Índice de Vulnerabilidade Social (IVS), desenvolvido pelo Ipea (2015). 0 método de cálculo do IVS prevê três dimensões: (1) infraestrutura urbana, que capta as "condições de acesso aos serviços de saneamento básico e de mobilidade urbana" (ibid., p. 8); (2) capital humano, que determina "as perspectivas (atuais e futuras) de inclusão social dos indivíduos" (ibid., p. 9); e (3) renda e trabalho, que dimensiona a "insuficiência de renda presente [...] [e] um estado de insegurança de renda" (ibid., p. 10).

As três dimensões têm o mesmo peso no cálculo final: para obter cada uma, é utilizada uma série de indicadores que representam "[...] conjuntos de ativos, recursos ou estruturas, cujo acesso, ausência ou insuficiência indicam que o padrão de vida das famílias se encontra baixo, sugerindo, no limite, o não acesso e a não observância dos direitos sociais". (ibid., p. 8). Cada indicador varia de 0,000 (situação ideal) a 1,000 (pior situação); e, para se chegar a esse valor, cada variável que reflete seu respectivo indicador passa por uma padronização, para que todas tenham a mesma escala.

Após padronizar, o índice é obtido conforme a equação abaixo. Em outros termos, o IVS obtido, para cada unidade i, é a média aritmética de seus três componentes: Infraestrutura Urbana (IU); Capital Humano (CH); e Renda-Trabalho (RT). Os 16 indicadores utilizados para cada um dos componentes estão em Ipea (ibid., pp. 8-10).

$$
I V S_{i}=\frac{1}{3}\left(I U_{i}+C H_{i}+R T_{i}\right), \quad 0 \leq I V S_{i} \leq 1
$$

Os resultados do IVS são divididos em 5 grandes grupos (ou faixas) de vulnerabilidade: muito baixa $(0,000$ a 0,200$)$; baixa $(0,201$ a 0,300); média $(0,301$ a 0,400); alta $(0,401$ a 0,500); e muito alta $(0,501$ a 1,000).

Quanto à unidade espacial de análise, o IVS é apresentado em unidades menores do que as áreas de ponderação, porém maiores do que os setores censitários em si. Os formuladores criaram áreas que são chamadas de Unidades de Desenvolvimento Humano (UDHs), as quais são:

[...] áreas mais homogêneas, do ponto de vista das condições socioeconômicas, do que as áreas de ponderação do IBGE. Ou seja, elas são construídas com o objetivo de melhor captar a diversidade de situações relacionadas com o desenvolvimento humano que ocorre no interior dos espaços intrametropolitanos, para desvendar 0 que é escondido pelas médias municipais agregadas. Enquanto a lógica das áreas de ponderação do IBGE atende aos quesitos técnicos relacionados ao processo de coleta e amostragem, as UDHs estão voltadas para a análise espacial das RMs por meio de recortes espaciais de maior homogeneidade socioeconômica, com 0 objetivo de retratar as desigualdades intrametropolitanas [...]. (Ibid., p. 13)

Já que os dados do Censo Demográfico são disponíveis para as áreas de ponderação (APs), e as UDHs são unidades menores, vamos 
realizar todas as análises para as áreas de ponderação. Na maioria dos casos, uma área de ponderação contém várias UDHs; todavia, há alguns casos em que uma UDH está dividida entre duas áreas. Para resolver o problema, e obter uma solução homogênea, foi adotada a seguinte estratégia:

1) cada setor censitário está em uma única UDH e uma única AP ao mesmo tempo;

2) atribui-se, ao setor censitário, o valor do IVS da UDH à qual pertence;

3) como cada AP é formada por vários setores, faz-se a média ponderada do IVS;

4) para realizar a média ponderada, utilizou-se o total populacional de cada setor;

5) deste modo, obtém-se o valor do IVS para cada área de ponderação.

Após esse processo de adequação - para que todas as variáveis se refiram às áreas de ponderação -, realiza-se a análise em três estágios. Primeiro, é feita uma análise de cluster pelo método $k$-means ${ }^{6}$ - usando as variáveis "tempo de deslocamento", "renda familiar per capita" e "grupamento de atividade" -, que garante homogeneidade interna e heterogeneidade externa entre os grupamentos (Hair et al., 2005). Em seguida, realiza-se a espacialização dos clusters, para verificar sua consistência enquanto representação da estrutura metropolitana paulista e, de fato, dimensioná-la. Finalmente, os resultados de cada cluster são confrontados com a distribuição dos arranjos familiares e com uma análise de homogeneidade do IVS categorizado, com o intuito de averiguar se: (1) há relação entre a estrutura urbana e a composição dos arranjos familiares; e (2) há sinais de convergência para algum padrão de vulnerabilidade dentro de cada cluster.

\section{Interações \\ família-estruturação urbana na RMSP}

Após a execução da análise de clusters pelo método $k$-means, foi possível observar que estes têm características bem distintas entre si, tanto em termos analíticos (Tabela 1) como espaciais (Mapa 1). As zonas de emprego e residencial elitizada têm níveis de vulnerabilidade muito baixos (no caso da primeira, bem próximos de zero), enquanto as zonas periféricas e intermediária II têm índices médios de vulnerabilidade. Ademais, nota-se que o número de áreas de ponderação em clusters mais abastados é significativamente menor do que os pertencentes às zonas intermediárias e periféricas: nas zonas de emprego e elitizada, há um total de 102 áreas, contra 306 nas intermediárias e 225 na periferia.

A respeito do tempo de deslocamento, nota-se que, nas zonas de emprego e residencial elitizada, mais de $80 \%$ dos trabalhadores demoram menos de 1 hora para chegar até 0 local do emprego. Por sua vez, ao avançar para as zonas intermediárias, aumenta a porcentagem de pessoas que demoram de 1 a 2 horas (na zona intermediária II são $28,4 \%$ e na periférica I, 37,2\%) e, na zona periférica I, há uma proporção expressiva de pessoas que demoram acima de 2 horas (mais de 15\%). Isto mostra que os trabalhadores dessas zonas têm maior probabilidade de se dirigirem para o centro da RMSP. Por fim, na zona periférica II, mais de $80 \%$ dos trabalhadores demoram até 1 hora para se deslocar até o emprego, o que pode refletir na permanência destes fora das zonas de emprego e elitizada. 


\section{Tabela 1 - Centróides das variáveis utilizadas para os clusters encontrados na RMSP, 2010}

\begin{tabular}{|c|c|c|c|c|c|c|c|}
\hline \multirow{3}{*}{\multicolumn{2}{|c|}{ Clusters }} & \multirow{3}{*}{$\begin{array}{l}\text { Zona de } \\
\text { emprego }\end{array}$} & \multicolumn{5}{|c|}{ Zonas Residenciais } \\
\hline & & & \multirow{2}{*}{ Elitizada } & \multicolumn{2}{|c|}{ Intermediária } & \multicolumn{2}{|c|}{ Periférica } \\
\hline & & & & I & II & $\mathbf{I}$ & II \\
\hline \multicolumn{2}{|c|}{ IVS (Índice de Vulnerabilidade Social) } & 0,087 & 0,161 & 0,244 & 0,333 & 0,367 & 0,32 \\
\hline \multirow{5}{*}{ 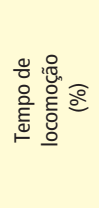 } & Até 5 minutos & 6,37 & 6,52 & 5,99 & 4,14 & 3,88 & 6,20 \\
\hline & De 6 a 30 minutos & 44,42 & 41,13 & 36,91 & 24,68 & 17,05 & 41,34 \\
\hline & De 31 a 60 minutos & 36,90 & 34,65 & 35,35 & 37,38 & 25,97 & 32,26 \\
\hline & De 61 a 120 minutos & 10,78 & 15,63 & 18,84 & 28,42 & 37,18 & 16,36 \\
\hline & Acima de 120 minutos & 1,53 & 2,07 & 2,89 & 5,38 & 15,92 & 3,84 \\
\hline \multirow{8}{*}{ 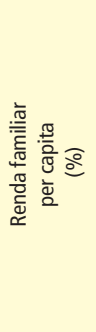 } & Abaixo de $1 / 4$ SM & 7,29 & 5,29 & 7,26 & 11,23 & 13,94 & 10,16 \\
\hline & De $1 / 4$ a $1 / 2$ SM & 1,13 & 2,27 & 4,92 & 10,72 & 14,33 & 11,23 \\
\hline & De $1 / 2$ a $1 \mathrm{SM}$ & 3,67 & 8,69 & 16,49 & 27,70 & 31,86 & 28,23 \\
\hline & De 1 a 2 SM & 8,99 & 20,62 & 31,43 & 32,58 & 29,59 & 32,66 \\
\hline & De 2 a 3 SM & 7,69 & 14,04 & 15,68 & 9,71 & 6,50 & 9,35 \\
\hline & De 3 a 5 SM & 13,75 & 18,00 & 13,18 & 5,40 & 2,80 & 5,28 \\
\hline & De 5 a 10 SM & 25,50 & 19,25 & 8,41 & 2,17 & 0,80 & 2,33 \\
\hline & Acima de 10 SM & 31,99 & 11,84 & 2,62 & 0,50 & 0,18 & 0,75 \\
\hline \multirow{8}{*}{ 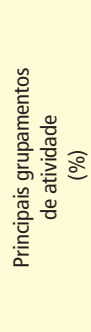 } & Comércio e reparo de objetos & 16,28 & 24,52 & 27,08 & 24,88 & 23,81 & 23,17 \\
\hline & Serviços prestados a empresas & 27,49 & 20,63 & 16,85 & 14,38 & 13,21 & 11,65 \\
\hline & Atividades mal especificadas & 16,89 & 17,02 & 16,18 & 15,59 & 14,59 & 18,14 \\
\hline & Serviços domésticos & 7,90 & 5,69 & 7,66 & 12,59 & 16,21 & 12,90 \\
\hline & Construção & 4,31 & 5,21 & 6,58 & 11,70 & 15,27 & 13,23 \\
\hline & Saúde e serviços sociais & 15,57 & 12,31 & 9,23 & 6,95 & 5,68 & 5,95 \\
\hline & Educação & 10,08 & 11,11 & 9,70 & 6,05 & 5,01 & 6,81 \\
\hline & Transporte terrestre & 1,48 & 3,51 & 6,72 & 7,87 & 6,22 & 8,14 \\
\hline \multicolumn{2}{|c|}{ Número de áreas de ponderação } & 35 & 67 & 125 & 181 & 88 & 137 \\
\hline
\end{tabular}

Fonte: Censo Demográfico de 2010 (IBGE) e Atlas da Vulnerabilidade Social (Ipea).

A respeito da renda familiar per capita (RFPC), nota-se que, quanto mais distante estiver uma área de ponderação em relação à zona de emprego, menor a proporção de famílias com 3 salários mínimos ou mais. Nas zonas periféricas e intermediária II, cerca de metade das famílias tem RFPC até 1 salário mínimo. Já, na zona elitizada, há maior heterogeneidade de situações, com $3 / 4$ das famílias distribuídas entre 1 e 10 salários mínimos. Depreende-se que, de modo geral, há uma relação espacial clara: menor a distância do centro - do que decorre um menor tempo médio de deslocamento -, maior a proporção de famílias com alta renda per capita.

No que tange às principais atividades de trabalho - apenas dentre os grupos com maior participação - em cada cluster, predominam o comércio e os serviços prestados a empresas. Entretanto, na zona de emprego e na 


\section{Mapa 1 - Áreas de ponderação da RMSP segundo cluster de pertencimento e municípios (2010)}

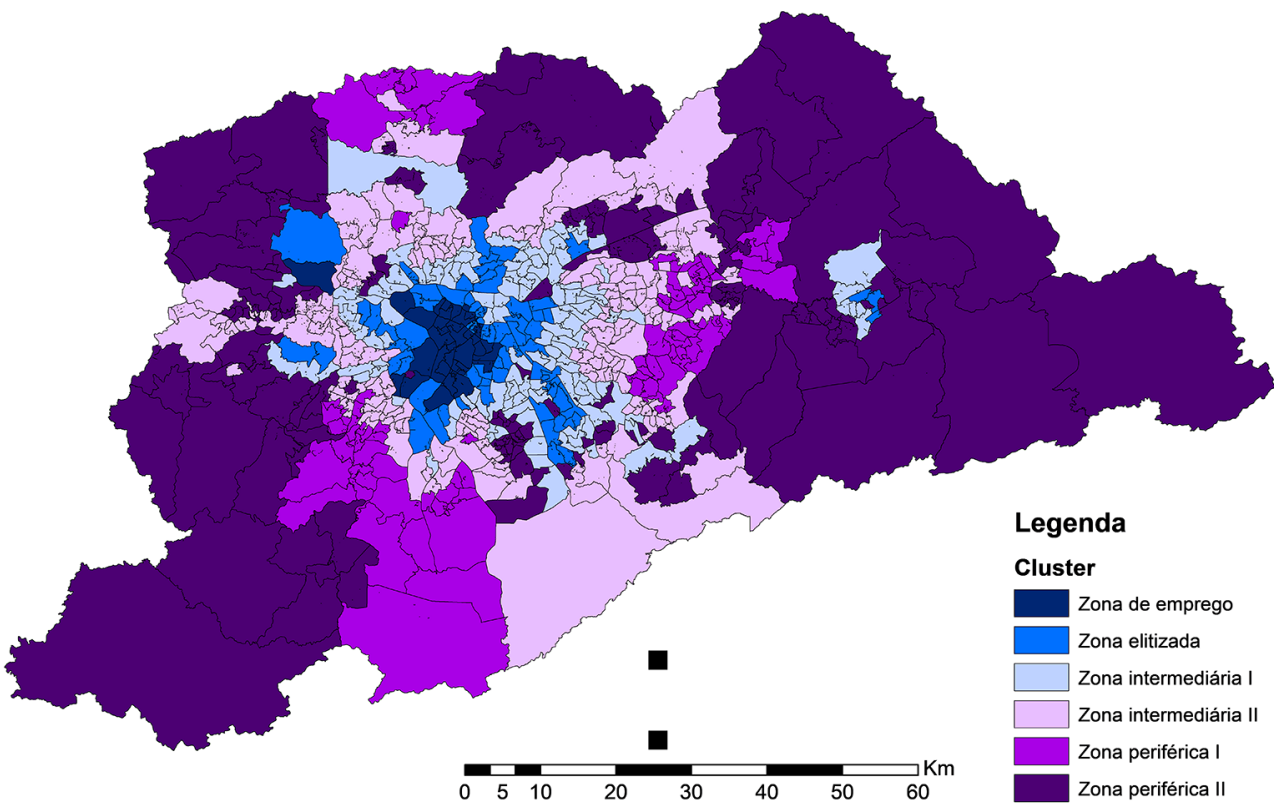

Fonte: Censo Demográfico de 2010 (IBGE) e Atlas da Vulnerabilidade Social (Ipea).

zona residencial elitizada, aparecem também percentuais expressivos de trabalhadores das áreas de saúde, educação e serviços sociais. Por sua vez, nas zonas residenciais intermediárias e periféricas, há uma proporção mais relevante de trabalhadores no setor de serviços domésticos e de transporte terrestre.

Os seis clusters abaixo encontrados se alocaram, espacialmente, da forma esperada (Mapa 1), com as zonas de emprego e residencial elitizada concentradas nas regiões centrais, enquanto as zonas residenciais intermediárias e periféricas estão, de fato, nas áreas menos abastadas. Encontram-se, ademais, algumas áreas de ponderação fora do centro que estão nas zonas de emprego ou elitizada, como é o caso de Santana do Parnaíba, Barueri, Cotia e Osasco (a oeste da capital). A espacialização mostrou que as áreas na zona periférica I e na zona intermediária II são as mais distantes da zona de emprego, o que explica o porquê de os trabalhadores residentes nessas áreas demorarem mais para chegar ao trabalho. Por sua vez, o fato de os residentes na zona periférica II demorarem menos que os da zona periférica I indica que os primeiros tendem a trabalhar fora da capital paulista. 
No que diz respeito à sobreposição dos clusters encontrados com a distribuição dos arranjos domiciliares (Tabela 2), é perceptível um fenômeno dual. Por um lado, as áreas contidas nas zonas de emprego e elitizada têm menor proporção de arranjos do tipo "casal com filhos" (31,2 e 38,6\%, respectivamente) e maior de unipessoais $(25,7$ e 17,0\%) em relação às outras. Por outro lado, nas áreas intermediárias e periféricas, a proporção de famílias "casal com filhos" é preponderante (oscilando entre 45 e $53 \%$ ), além de haver maior presença de arranjos do tipo monoparental feminino com filhos (cerca de 1 em cada 7 nas zonas periféricas e intermediárias).

Comparando com os resultados de Champion (2001) para as metrópoles americanas, observam-se padrões semelhantes aos encontrados pelo autor, com especificidades próprias da estrutura metropolitana paulista. A predominância das famílias de composição "nuclear burguesa" (casal com filhos) foi um fenômeno apontado pelo autor supracitado para o contexto americano, que também se verificou aqui. No entanto, naquele caso, as zonas residenciais mais afastadas do núcleo metropolitano correspondiam às áreas mais abastadas; já, na RMSP, tais áreas são as de menor status socioeconômico.

Tal condição leva à reflexão sobre quais fatores geraram esse panorama, tendo em vista que aqueles levantados por Champion (ibid.), para os subúrbios americanos (sobretudo os relativos às melhores condições para cuidar dos filhos), não se verificam para as periferias das tradicionais regiões metropolitanas brasileiras. De fato, o que se evoca para explicar a ocupação destes últimos espaços se refere a fatores macroestruturais ligados ao fenômeno da segregação residencial que, mediante as dinâmicas dos mercados de trabalho e de terras metropolitano, determina que grupos sociais vão ocupar que áreas.

Tabela 2 - Distribuição (\%) dos arranjos domiciliares por cluster na RMSP (2010)

\begin{tabular}{|c|c|c|c|c|c|c|c|}
\hline & \multirow{3}{*}{ Clusters } & \multirow{3}{*}{$\begin{array}{c}\text { Zona de } \\
\text { emprego }\end{array}$} & \multicolumn{5}{|c|}{ Zonas Residenciais } \\
\hline & & & \multirow{2}{*}{ Elitizada } & \multicolumn{2}{|c|}{ Intermediária } & \multicolumn{2}{|c|}{ Periférica } \\
\hline & & & & I & II & I & II \\
\hline \multirow{7}{*}{ 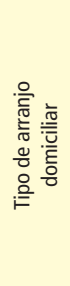 } & Casal sem filhos & 21,9 & 20,9 & 19,3 & 17,0 & 15,8 & 17,6 \\
\hline & Casal com filhos & 31,2 & 38,6 & 45,2 & 50,8 & 52,8 & 52,1 \\
\hline & Mãe com filhos & 9,9 & 12,2 & 14,1 & 14,9 & 15,2 & 13,5 \\
\hline & Pai com filhos & 1,5 & 1,9 & 1,9 & 1,9 & 1,8 & 1,8 \\
\hline & Outros arranjos familiares & 6,9 & 7,7 & 6,9 & 5,8 & 5,4 & 5,3 \\
\hline & Domiciílios unipessoais & 25,7 & 17,0 & 11,9 & 9,2 & 8,6 & 9,3 \\
\hline & Domicílios de não-parentes & 2,9 & 1,7 & 0,6 & 0,4 & 0,3 & 0,4 \\
\hline
\end{tabular}

Fonte: Censo Demográfico de 2010 (IBGE) e Atlas da Vulnerabilidade Social (Ipea). 
Se, portanto, as causas da seletividade social para a ocupação das zonas residenciais em questão são relativamente conhecidas, a seletividade demográfica, sobretudo em termos de arranjos familiares, ainda permanece uma incógnita. De fato, alguns estudos (Cunha, 1994; Jakob, 2003) avançaram na percepção de que as famílias predominantemente se encontram em estágios mais iniciais de seu ciclo de vida, não podendo arcar com os altos preços do solo impostos para a ocupação de zonas residenciais mais próximas à zona de emprego. No entanto, esses esforços de pesquisas não cobriram as lacunas quanto ao porquê da predominância dos arranjos familiares parsonianos.

Uma das hipóteses aventadas pelo presente estudo encontra-se justamente na questão referente à diferenciação de estágios dos regimes demográficos entre as diferentes zonas da estrutura metropolitana paulista. Fato é que, apesar da generalizada queda de fecundidade para a população com um todo no Brasil, existem importantes diferenciais de do fenômeno entre os diferentes grupos sociais, os quais podem, sim, explicar a maior vigência de arranjos familiares mais numerosos (incluídos casais com filhos e famílias monoparentais de chefia feminina) nas zonas residenciais periféricas, onde predominam os grupos sociais que estão na base da pirâmide social.

Acerca dos arranjos unipessoais, percebe-se uma correlação maior com o que foi observado por Champion (2001) para as innercities americanas. No entanto, pautando-se nos resultados de Nakano (2015), em seu estudo sobre os padrões de ocupação do centro da cidade de São Paulo, pode-se dizer que os arranjos domiciliares com idosos, especialmente os unipessoais, são predominantes. Nesse caso, as mesmas dinâmicas imobiliárias, em especial aquelas relacionadas ao mercado de terras mais valorizado nas áreas em questão, explicam a maior vigência dos arranjos domiciliares com indivíduos em fases mais avançadas de seu curso de vida.

No entanto, iniciativas relacionadas à reocupação da innercity paulistana em um padrão de maior densidade demográfica estão em curso. Ainda que timidamente, esse fenômeno passa a ser visto por meio do crescimento de lançamentos imobiliários com menor metragem por unidade, voltados aos arranjos domésticos unipessoais ou do tipo "casal sem filhos". Em muitos desses casos, os argumentos de venda são justamente aqueles levantados por Champion (2001) para explicar a localização nos núcleos metropolitanos pelos arranjos domiciliares citados acima: a proximidade do emprego e dos equipamentos culturais.

Isto nos mostra que o padrão de convivência nas áreas mais abastadas é significativamente diferente do encontrado nas áreas mais vulneráveis. Ademais, podemos concluir que, com o tempo e o desenvolvimento de áreas hoje menos abastadas, é possível que se avance rumo a um padrão residencial mais próximo do atualmente encontrado tanto na zona de emprego como na zona elitizada. Além disto, é possível que variáveis, como a de rendimento familiar per capita, tenham uma meIhora generalizada, enquanto o tempo de deslocamento até o trabalho (e a localização dos empregos) se altere com o desenvolvimento e a reestruturação urbana em curso.

Finalmente, é possível observar a questão da homogeneidade dos clusters no que diz respeito ao grupo IVS, ao qual cada área de ponderação pertence (Tabela 3). Nota-se que, 
Tabela 3 - Distribuição (\%) dos grupos do IVS por cluster na RMSP (2010)

\begin{tabular}{|c|c|c|c|c|c|c|c|}
\hline & \multirow{3}{*}{ Clusters } & \multirow{3}{*}{$\begin{array}{l}\text { Zona de } \\
\text { emprego }\end{array}$} & \multicolumn{5}{|c|}{ Zonas Residenciais } \\
\hline & & & \multirow{2}{*}{ Elitizada } & \multicolumn{2}{|c|}{ Intermediária } & \multicolumn{2}{|c|}{ Periférica } \\
\hline & & & & $\mathbf{I}$ & II & $\mathbf{I}$ & II \\
\hline \multirow{4}{*}{ 을논 } & Muito baixo $(0,000$ a 0,200$)$ & 97,1 & 70,1 & 15,2 & - & - & 0,7 \\
\hline & Baixo $(0,201$ a 0,300$)$ & 2,9 & 29,9 & 78,4 & 12,7 & - & 27,0 \\
\hline & Médio $(0,301$ a 0,400$)$ & - & - & 6,4 & 85,6 & 87,5 & 70,1 \\
\hline & Alto $(0,401$ a 0,500$)$ & - & - & - & 1,7 & 12,5 & 2,2 \\
\hline
\end{tabular}

Fonte: Censo Demográfico de 2010 (IBGE) e Atlas da Vulnerabilidade Social (Ipea).

na zona de emprego, a homogeneidade é mais expressiva (quase a totalidade das áreas no cluster tem IVS abaixo de 0,200) do que nas zonas intermediárias e periféricas e, até mesmo, na zona elitizada. Ainda que uma categoria contenha a maioria absoluta das áreas de cada cluster, sempre há outra, minimamente relevante, nas áreas residenciais. Embora seja um indício bastante simples e até certo ponto questionável, isto mostra que, quanto mais próxima estiver uma área de ponderação do cluster central, mais homogênea tende a ser a região.

\section{Possíveis desdobramentos}

0 presente exercício de reflexão, para além de responder ao questionamento que funda suas pautas de pesquisa, suscitou novas questões e vias de discussão, tanto pelo debate teórico (colocado à tona na primeira parte do ensaio), quanto pelo encaminhamento empírico seguido posteriormente para a realidade apresentada para a RMSP. No que toca o plano teórico, fica claro, mesmo com os poucos modelos de arranjos domésticos resgatados da bibliografia sobre o tema, que os processos de estruturação urbana e heterogeneização dos arranjos familiares possuem profundas imbricações que não podem ser ignoradas nos estudos sobre essas temáticas.

Por fim, tanto por parte das mudanças no regime sociodemográfico e do processo de reestruturação urbana, quanto por parte das possíveis interações entre eles, sabe-se que muitos dos elementos utilizados para o debate e suas conclusões se encontram restritos ao contexto urbano-metropolitano dos países desenvolvidos. Essa perspectiva de análise, em linhas gerais, confirmou-se para a metrópole paulistana. Isso porque, como evidenciado pela análise de cluster, essa aglomeração possui uma estrutura mononuclear, com um rebatimento espacial da estratificação socioeconômica das zonas residenciais relativamente distinto da realidade encontrada nas metrópoles americanas, tendo em vista que os grupos sociais mais abastados vivem mais próximos ao núcleo metropolitano, 
acontecendo o inverso à medida que se desce na pirâmide social.

De qualquer modo, entre as zonas residenciais periféricas e centrais, observou-se um padrão parecido com o americano, já que os arranjos familiares "burgueses" (casais com filhos) tenderam a ter maior participação nas zonas residenciais elitizadas, mas, sobretudo, nas zonas residenciais intermediárias e periféricas, mais distantes do centro. Por sua vez, os arranjos unipessoais e de casais sem filhos registraram maior peso nas zonas de emprego e residencial elitizada, na qual se pressupõe que estejam mais avançados tanto o processo de reestruturação urbana quanto o de heterogeneização dos arranjos familiares. Finalmente, pôde-se também observar certa homogeneidade no que diz respeito ao nível de vulnerabilidade encontrado para as áreas do cluster central, sendo que essa homogeneidade se reduz com o afastamento rumo às zonas intermediárias e periféricas.

Conclusivamente, este trabalho propôs-se a analisar as múltiplas realidades encontras na RMSP, entendida como a mais desenvolvida e na qual se poderiam encontrar padrões mais próximos dos existentes - a partir da literatura - no contexto norte-americano e, em geral, nos países desenvolvidos. Muito resta a ser discutido no que tange às relações entre (re)estruturação do espaço urbano, vulnerabilidade social e distribuição dos arranjos domiciliares (à luz das contínuas mudanças demográficas experimentadas pelo Brasil). Todavia, apresentou-se aqui um primeiro esforço de entrelaçar as diversas dimensões, mostrando a multiplicidade de relações que se apresentam, atualmente, no tecido urbano da metrópole paulista.

[I] https://orcid.org/0000-0003-1389-3082

Universidade Estadual de Campinas, Faculdade de Ciências Aplicadas, Laboratório de Economia e Gestão. Limeira, SP/Brasil.

dpierf@gmail.com

[II] https://orcid.org/0000-0003-0399-7830

Universidade Estadual de Campinas, Coordenadoria de Centros e Núcleos, Núcleo de Estudos de População "Elza Berquó". Campinas, SP/Brasil.

fariasax@uol.com.br 


\section{Notas}

(1) Utilizamos "unidade doméstica" como tradução mais aproximada para o termo household, corrente na literatura americana, que também é uma das unidades de análise nos levantamentos locais. Segundo Cavenaghi e Alves (2011, p. 23), "En general, la unidad doméstica o de producción se define por las necesidades habitacionales o de alimentación y puede tener diversos tamaños (incluso estar compuesta de un solo individuo)". Especialmente em sua apreensão sociológica, o conceito de família distingue-se da noção de unidade doméstica, já que relações de parentesco e redes de apoio podem ultrapassar os limites do domicílio ou não corresponderem a determinados arranjos, como no caso dos domicílios unipessoais. Neste trabalho, no entanto, optamos por utilizar os termos de maneira intercambiável, uma vez que tendem a coincidir na maioria dos casos.

(2) Ver Lesthaeghe e Van de Kaa (1986).

(3) Segundo Camarano et al. (2004), arranjos domiciliares com idosos são aqueles cujo idoso é o responsável pelo domicílio, associando-se sua condição de funcionalidade/autonomia. Por sua vez, arranjos domiciliares de idosos são aqueles cujo idoso mora na condição de parentes do responsável do domicílio, associando-se uma condição de vulnerabilidade.

(4) Para Courgeau (1988), os espaços de vida, em linhas gerais, compreendem a área que os indivíduos ocupam em seu dia a dia para o desenvolvimento de atividades, como trabalho, estudo ou qualquer outra relacionada à sua reprodução social e material, seja dentro do município ou envolvendo outros além do de residência.

(5) O termo innercity, utilizado aqui a partir de Champion (2001), refere-se ao que se chama no Brasil de núcleo metropolitano, área das aglomerações urbanas em que se concentram o mercado de trabalho (employment field) e toda a estrutura de serviços e comércio. No caso americano tratado pelo autor, essa área se opõe àquelas residenciais que se localizam ao seu redor, especialmente nas metrópoles monocêntricas.

(6) Para a realização da análise, definiram-se 6 agrupamentos. Essa escolha procurou se aproximar da segmentação do tecido urbano metropolitano, distinguindo entre: (1) zonas residenciais de zonas de emprego (employment fields); (2) áreas residenciais por estrato socioeconômico; e (3) os diversos graus de heterogeneidade das áreas periféricas. Desse modo, procuraram-se obter os seguintes clusters: zonas de emprego; zona residencial elitizada; zonas residenciais intermediárias I e II; e zonas residenciais periféricas I e II. 


\section{Referências}

ALVES, J. E.; CAVENAGHI, S. e BARROS, L. (2010). “A Família DINC no Brasil: algumas características socioeconômicas". Texto para discussão ENCE, n. 30.

BENKO, G. (1996). Economia, espaço e globalização: na aurora do século XXI. São Paulo, Hucitec.

BENNETT, J. e DIXON, M. (2006). Single person households and social policy: looking forwards. Nova York, Joseph Rowntree Foundation.

BILAC, E. D. (1995). "Sobre as transformações nas estruturas familiares. Notas muito preliminares". In: RIBEIRO, I. e RIBEIRO, A. C. T. (orgs.). Famílias em processos contemporâneos: inovações culturais na sociedade brasileira. São Paulo, Loyola.

BUZAR, S.; OGDEN, P. e HALL, R. (2005). Households matter: the quiet demography of urban transformation. Progress in Human Geography, v. 29, n. 4, pp. 413-436.

CAMARANO, A. A. et al. (2004). "Famílias: espaço de compartilhamento de recursos e vulnerabilidades". In: CAMARANO, A. A. (org.). Os novos brasileiros: muito além dos 60? Rio de Janeiro, Ipea.

CAVENAGHI, S. e ALVES, J. E. (2011). “Domicilios y familias en la experiencia censal del Brasil: cambios y propuesta para identificar arreglos familiares". Notas de población, n. 92.

CHAMPION, A. (2001). A changing demographic regime and evolving polycentric urban regions: consequences for the size, composition and distribution of city populations. Urban Studies, v. 38, n. 4, pp. 657-677.

CLARK, W. (1987). The Roepke lecture in economic geography: urban restructuring from a demographic perspective. Economic Geography, n. 63, pp. 103-125.

CLARK, W. e WITHERS. S. (2007). Family migration and mobility sequences in the United States: spatial mobility in the context of the life course. Demographic Research, v. 17, n. 20, pp. 591-622.

COURGEAU, D. (1988). Méthodes de mesure de la mobilité spaciale: migration internes, mobilité temporaire, navettes. Paris, Ined.

CUNHA, J. M. (1994). Mobilidade populacional e expansão urbana: o caso da Região Metropolitana de São Paulo. Tese de Doutorado. Campinas, Universidade Estadual de Campinas.

(2011). Mobilidade espacial da população: desafios teóricos e metodológicos para o seu estudo. Campinas, Nepo/Unicamp.

DAVANZO, A. et al. (2011). “Metropolização e Rede Urbana”. In: Pereira, R. e Furtado B. (orgs.). Dinâmica urbano-regional: rede urbana e suas interfaces. Brasília, Ipea.

FARIAS, L. A. (2013). A cidade sob a reestruturação urbana: revisitando o conceito com o caso do Rio de Janeiro. XIII SIMPURB. Rio de Janeiro, Uerj, pp. 1-16.

FINDLAY, A. e ROGERSON, R. (1993). “Migration, places and quality of life: voting with their feet?". In: CHAMPION, A. (ed.). Population matters: the local dimension. Londres, Paul Chapman Publishing.

GOMES, M. T. S. (2011). O debate sobre a reestruturação produtiva no Brasil. RA'E GA, v. 21, pp. 51-77.

HAIR, J. F. et al. (2005). Análise multivariada de dados. São Paulo, Bookman.

HALL, R. e OGDEN, P. (2003). Living alone in inner London: trends among the population of working age. Environment and Planning A, v. 35, pp. 871-888. 
HARVEY, D. (1993). A condição pós-moderna. São Paulo, Loyola.

IPEA (2015). Atlas da vulnerabilidade social nas regiões metropolitanas brasileiras. Brasília, Ipea.

JAKOB, A. A. (2003). Análise sociodemográfica da constituição do espaço urbano da Região Metropolitana da Baixada Santista no período 1960-2000. Tese de Doutorado. Campinas, Universidade Estadual de Campinas.

KNOX, P. (1994). Urbanization: an Introduction to urban geography. Englewood Cliffs, Prentice-Hall.

LESTHAEGHE, R. e VAN DE KAA, D. (1986). “Twee Demografische Transities?”. In: LESTHAEGHE, R. e VAN DE KAA, D. (eds.). Bevolking: Groei en Krimp, Mens en Maatschappij. Deventer, Van Loghum-Slaterus.

NAKANO, A. (2015). Elementos demográficos sobre densidade urbana: São Paulo, uma cidade oca? Tese de Doutorado. Campinas, Universidade Estadual de Campinas.

OLIVEIRA, M. C.; MARCONDES, G. e VIEIRA, J. M. (2015). "Cinquenta anos de relações de gênero e geração no Brasil: mudanças e permanências". In: ARRETCHE, M. (org.). Trajetórias das desigualdades: como o Brasil mudou nos últimos 50 anos. São Paulo, Unesp.

RIBEIRO, W. S. (2009). "O papel das cidades médias diante da reestruturação urbana”. In: BICALHO, A. M. e GOMES, P. C. (orgs.). Questões metodológicas e novas temáticas na pesquisa geográfica. Rio de Janeiro, Publit.

SANTOS, J. (2008). Reestruturação urbana x reestruturação da cidade: o caso de Salvador. In: X COLOQUIO INTERNACIONAL DE GEOCRÍTICA. Barcelona, Universitat de Barcelona.

SOJA, E. (1993). Geografias pós-modernas: a reafirmação do espaço na teoria social crítica. Rio de Janeiro, Zahar.

SPOSITO, M. (2004). O chão em pedaços: urbanização, economia e cidades no Estado de São Paulo. Livre-docência. Presidente Prudente, Universidade Estadual Paulista.

THERBORN, G. (2006). Sexo e poder: a família no mundo (1900-2000). São Paulo, Contexto.

VILLAÇA, F. (1999). “Uma contribuição para a história do planejamento urbano no Brasil”. In: DEÁK, C. e SCHIFFER, S. R. (orgs.). O processo de urbanização no Brasil. São Paulo, Edusp.

WATTERS, E. (2003). Urban tribes: a generation redefines friendship, family, and commitment. Londres e Nova York, Bloomsbury.

Texto recebido em 12/maio/2018

Texto aprovado em 22/ago/2018 